\title{
Persistent Minor Blips of HIV Viral Load in Patients on ART Are Associated With Virological Failure and Higher Rates of Clinical Events.
}

\section{Enrique BERNAL ( $\sim$ ebm.hgurs@gmail.com )}

Hospital General Universitario Reina Sofía \& Murcia University

\section{Angeles MUÑOZ}

Hospital General Universitario Reina Sofía \& Murcia University

Maria Jose ALCARAZ

Hospital General Universitario Reina Sofía \& Murcia University

Antonia ALCARAZ

Hospital General Universitario Reina Sofía \& Murcia University

\section{Mar MASIA}

Hospital General de Elche \& University Miguel Hernández

Joaquín BRAVO

Hospital Universitario Morales Meseguer

Jose Ramón BLANCO

Hospital San Pedro

\section{Sergio REUS}

Hospital General Universitario de Alicante

\section{Miguel GORGOLAS}

Hospital Universitario Fundación Jiménez Díaz

Josu Mirena BARAIA-ETXABURO

Hospital de Basurto

\section{Alexandre PEREZ}

Hospital Alvaro Cunqueiro

\section{Alfredo CANO}

Hospital General Universitario Reina Sofía \& Murcia University

Félix GUTIERREZ

Hospital General de Elche \& University Miguel Hernández

\section{CoRIS Study}

Hospital General Universitario Reina Sofía \& Murcia University 
Keywords: Viral load elevations, low-level viremia, virological failure, AIDS/death and non-aids events Posted Date: March 12th, 2021

DOI: https://doi.org/10.21203/rs.3.rs-282526/v1

License: (c) (1) This work is licensed under a Creative Commons Attribution 4.0 International License. Read Full License 


\section{Abstract}

Objective: To investigate the long-term impact of plasma VL elevations between 50 and $199 \mathrm{copies} / \mathrm{ml}$ (VLE50-199) on virological failure and development of AIDS, death or non-AIDS events (NAE) in patients receiving ART.

Methods: We analyzed ART-naïve adults from the cohort of the Spanish AIDS Research Network (CoRIS) who initiated ART from 2012 to 2017 and achieved $V L<50$ copies/ml within 3-9 months after ART initiation. Elevations of VL between 50 and 199 copies/ml were divided into uncommon ( $<25 \%$ of the measurements) or not viral elevation, frequent (25-50\%) and very frequent ( $>50 \%$ of the measurements). Multivariate Cox models were used.

Results: Of 4121 patients included, 3881 (94.2\%) patients VLE50-199 was uncommon or was not present. VLE50-199 was frequent in $185(4.5 \%)$ and very frequent in 55 (1.3\%) patients. 169 had virological failure (4.1\%), 57 (1.38\%) patients died or developed an AIDS event and 107 (2.6\%) developed NAE. Frequent VLE50-199 (aHR, 11.83; 95\% Cl, 6.42-21.84; $\mathrm{p}<0.001)$ and very frequent VLE50-199 (aHR, 29.1; 95\% Cl, 12.6-67.19; $p<0.001$ ) were associated with a higher risk of virological failure, but did not increase the risk of developing AIDS events or death. Frequent VLE50-199 had an adjusted NAE hazard ratio of 2.13 (95\% $\mathrm{Cl}, 0.91-4.97 ; \mathrm{p}=0.081)$ and very frequent VLE50-199 of $4.66(95 \% \mathrm{Cl}, 0.9-21 ; \mathrm{p}=0.051)$.

Conclusion: Persistent mild elevations between 50 and 199 copies $/ \mathrm{ml}$ were strongly associated with an increased risk of virological failure and with higher rates of NAE. Therefore, closer monitoring of these patients may be warranted.

\section{Introduction}

Thanks to the introduction of antiretroviral treatment (ART), the morbidity and mortality of HIV-infected patients has been drastically reduced through its ability to suppress HIV replication[1]. The goal of ART is to reduce the HIV plasma viral load to the level of undetectability that is usually below $50 \mathrm{copies} / \mathrm{ml}$. Having an undetectable viral load has been associated with increased survival, a lower risk of AIDS and non-AIDS events and not spread the infection[2,3]. However, there are a group of patients who despite receiving a correct treatment do not reach or maintain this level of undetectability. Most studies have shown that having viral load levels above 200 copies $/ \mathrm{ml}$ are associated with an increased risk of virological failure [4-6], occurrence of resistance mutations[7] and AIDS/death events[6]. However, the effects of viral loads between 50 and 200 copies/ml are unknown. Although "blips" (transient elevations in viral load) have not been associated with an increased risk of events, it is unknown if an increase in their frequency could have a negative impact on the occurrence of virological and/or clinical events.

The objective of this study was to investigate the long-term impact of persistent or frequent viral load elevations between 50-199 copies/ml on the development of virological (virological failure) and clinical (AIDS, death and NAE events) events among HIV-infected patients receiving ART from a Spanish contemporary nationwide cohort. 


\section{Methods}

\section{Study population}

The cohort of Spanish AIDS Research Network (CoRIS) is an open, multicenter and prospective cohort of HIV-positive adults, naïve to ART at study entry, seen for the first time from January 2004 in any of the 42 centers from 13 of 17 Autonomous Regions in Spain. Subjects agreed to participate in the study by signing an informed consent form. Ethical approval for CoRIS was granted. A complete description of CoRIS has been published elsewhere[8]. Briefly, CoRIS collects a minimum dataset as provided for in the cohort protocol which includes baseline and follow-up of socio-demographic, immune-virological and clinical data including ART medication, with start and stop dates, as well as reasons for drug discontinuation. Furthermore, all centers are invited to provide data on incident non-AIDS events (NAEs), including non-AIDS-defining malignancies and cardiovascular, renal, liver, psychiatric, bone, and metabolic events[9]. Patients are followed periodically in accordance with routine clinical practice. For this study we have chosen the patients who started treatment from 2012 to 2017.

All methods were carried out in accordance with relevant guidelines and regulations and all experimental protocols were approved by Reina Sofia Hospital Ethics Committee.

Eligible individuals were antiretroviral naïve patients who initiated ART and remained on it for at least 6 months, $\geq 18$ years old and who achieved viral suppression, defined as plasma viral load below 50 copies/ml, within 3-9 months after ART initiation. Patients with no follow-up after viral suppression were excluded from the analyses. In addition, for analyses on association of VLE with first occurrence of any serious NAE, we also excluded individuals who were monitored in centers not providing data on NAEs.

\section{Definitions}

We defined viral load elevations below 200 copies/ml (VLE 50-199) as at least one viral load between 50 and $199 \mathrm{copies} / \mathrm{ml}$ after virological suppression. Following this definition, for descriptive purposes, individuals were classified into three groups: uncommon VLE50-199 or not elevation of viral load (viral load elevation between 50-199 copies/ $\mathrm{ml}$ in $<25 \%$ of the measurements or viral load $<50 \mathrm{copies} / \mathrm{ml}$ ), frequent VLE 50-199 (viral load elevation ranging from 50 to 199 copies $/ \mathrm{ml}$ between $25 \%$ and $50 \%$ of the measurements) and very frequent VLE 50-199 (viral load elevation between 50-199 copies/ml in more than $50 \%$ of the measurements).

We have also considered for the analysis those patients with non-consecutive elevations of the viral load higher than 200 copies and lower than 1000 copies. We denominate them VLE 200-999.

\section{Outcomes}

Outcomes of this study were experiencing first virological failure, defined as at least two consecutive viral loads more than 200 copies $/ \mathrm{ml}$ or one more than 1.000 copies $/ \mathrm{ml}$, occurrence of clinical events (first 
AIDS events or death) and first serious NAE [non-AIDS-defining malignancies, cardiovascular, renal, and liver-related] after virological suppression.

\section{Statistical analysis}

A descriptive analysis of patients' characteristics at ART initiation was carried out using frequency tables for categorical variables, and median and interquartile range (IQR) for continuous variables. Differences in socio-demographic and clinical characteristics between different groups of VLE (uncommon, frequent and very frequent) were assessed through the chi-squared test for independence for categorical variables, and the non-parametric Kruskal-Wallis tests for continuous variables.

A multivariable multinomial logistic regression model was fit to investigate sociodemographic and clinical factors associated with frequent VLE50-199 and very frequent VLE50-199 in comparison to uncommon VLE50-199.

For the analyses of association of VLE groups with first virological failure and clinical events after virological suppression, follow-up started at the date of the first viral load below 50 copies/ml within 3-9 months after ART initiation and ended at the date of the event of interest, date of last study contact or censoring date, whichever arose first. Analyses were right-censored 5 years after virological suppression due to low numbers of events observed thereafter.

For those three outcomes, VLE groups was analyzed as a time-varying covariate. We calculated causespecific cumulative incidence curves and used Cox proportional hazards models to estimate crude and adjusted hazard ratios. The proportional hazards assumption was checked graphically and by tests based on Schoenfeld residuals.

Multivariable models were adjusted for sex (male, female), age $(<50, \geq 50)$, transmission group (homo/bisexual, injecting drug use, heterosexual, other/unknown), educational level (compulsory education or not, upper secondary or university, unknown), country of origin (Spain, not Spain, unknown), CD $4+$ cell count $(<200, \geq 200$, unknown), HIV- 1 viral load $(<100000, \geq 100000$, unknown) and AIDS diagnosis (no, yes), hepatitis $C$ virus antibodies (no, yes, unknown), hepatitis B surface antigen (no, yes, unknown), ART regimen (2 nucleoside reverse transcriptase inhibitor [NRTI] + 1 non-nucleoside reverse transcriptase inhibitor [NNRTI], 2 NRTI + 1 [boosted protease inhibitor[PI/b], 2 NRTI + 1 integrase strand transfer inhibitor [INSTIs], other/non-specified) and duration of ART. Wald tests were used to derive pvalues. All statistical analyses were performed using SPSS Software (version 24) and r software.

\section{Results}

A total of $4121 \mathrm{HIV}$-infected patients were included in the study. The median age was 35 years (IQR, 28-42 years), $12.4 \%$ were female, median (IQR) baseline CD4+ count at ART initiation was 394 (255-545) cells $/ \mathrm{ml}$ and $38.1 \%$ started with INSTIs-based regimens. Six hundred and thirty-two (15.33\%) experienced 
at least one episode of VLE50-199 (582 patients with no VLE200-999). Median follow-up time after viral suppression was $1.9(\mathrm{IQR}, 0,78-3.07)$ years.

Sociodemographic and clinical characteristics at ART initiation according to the frequency of VLE are shown in Table 1. The median number of viral load measurements per individual after viral suppression was $5(\mathrm{IQR}, 3-8)$ in the uncommon group, $3(\mathrm{IQR}, 2-5)$ in the frequent group and $2(\mathrm{IQR}, 2-4)$ in the very frequent group. Results from the multivariate analysis showed that $\mathrm{VL} \geq 100000 \mathrm{copies} / \mathrm{mL}$ (OR, 8.96; $95 \% \mathrm{Cl}, 1.012-71.4)$ and a diagnoses of AIDS (OR, 1.46; 95\% $\mathrm{Cl}, 1.02-2.1)$ at ART initiation were associated with a higher risk of developing frequent VLE50-199, whereas likelihood significantly decreased with the duration of ART (OR, 0.802; $95 \% \mathrm{Cl}, 0.727-0.805)$.

\section{Virological outcome}

During follow-up, 169 instances of virological failure occurred (143 among patients with uncommon or not VLE50-199, 17 among patients experiencing frequent VLE50-199 and 9 among patients experiencing very frequent VLE50-199). Overall, $4.1 \%$ of the patients experienced virological failure after 2 years of viral suppression and this percentage was higher in patients experiencing very frequent VLE50-199 (16.4\%) than in those experiencing frequent VLE50-199 and uncommon VLE50-199 (9.2\% and 6.7\%, respectively) (Figure 1A).

After adjusting for patient characteristics, very frequent VLE50-199 (aHR, 29.1; 95\% Cl, $12.6-68.19$ ) and frequent VLE50-199 (aHR, 11.83; 95\% Cl, 6.42 - 21.84) were strongly associated with virological failure as compared with uncommon VLE50-199 or not elevation of viral load (Table 2).

\section{AIDS events or death}

During follow-up, 57 patients died or developed an AIDS event (51 in uncommon or not VLE50-199, 6 in frequent VLE50-199 and none in very frequent VLE50-199). Overall, $1.4 \%$ of the patients developed an AIDS event or died after 2 years of viral suppression; this percentage was $1.3 \%$ in patients with uncommon VLE50-199 and 3.2\% in those with frequent VLE50-199 (Figure 1B). In multivariable analyses, frequent VLE50-199 was no associated with higher risk of AIDS events or death (Table 2).

\section{Non-AIDS events}

During follow-up, 107 patients developed an NAE (97 in uncommon or not VLE50-199, 8 in frequent VLE50-199 and 2 in very frequent VLE50-199). Overall, after 2 years of viral suppression, $2.7 \%$ of the patients developed a NAE; this percentage was $2.6 \%$ in patients with uncommon VLE50-199, $4.4 \%$ in those with frequent VLE50-199 and 3.7\% in those with very frequent VLE50-199 (Figure 1C). In multivariable analyses, frequent VLE50-199 had an adjusted NAE hazard ratio of $2.13(95 \% \mathrm{Cl}, 0.91-4.97$; $\mathrm{p}=0.081)$ and very frequent VLE50-199 of $4.66(95 \% \mathrm{Cl}, 0.9-21 ; \mathrm{p}=0.05)$ (Table 2).

\section{Discussion}


In this cohort of HIV-infected patients receiving ART from 2012 to 2017, persistent minor elevations of plasma VL below 200 copies/mL were strongly associated with an increased risk of virological failure. Patients with VLE 50-199 in more than $25 \%$ of the determinations were more likely to develop virological failure, although they were not at higher risk of developing AIDS events or death in the long-term. The risk of virological failure was particularly high in patients with VLE 50-199 in more than 50\% of the measurements. We also observed higher rates of NAE in individuals with frequent and very frequent VLE50-199; however, this difference was not statistically significant in multivariate analysis. In contrast, not having VLE50-199 or having it in less than $25 \%$ of the measurements were not associated with a higher risk of developing any of the events analyzed. This observation is relevant since the prognostic implications and optimal management of patients who have VLE50-199 on ART remains poorly defined.

Although subjects included in these analyses started ART in the era of modern antiretroviral agents, a remarkable proportion of the patients experienced mild elevations of VL between 50 and $199 \mathrm{copies} / \mathrm{ml}$. Transient elevations of VL have been frequently reported in patients receiving ART in previous cohort studies[10,11]. Between 4 and $20 \%$ of HIV-infected patients experienced persistent episodes of detectable viremia at low levels, between 50 and $500 \mathrm{copies} / \mathrm{ml}$, in investigations conducted during the past decade[10-12]. There are multiple possible explanations for the viral load elevations phenomenon, but it is generally believed to arise from the release of the virus from resting memory CD $4+T$ lymphocytes activated upon antigenic stimulation $[13,14]$ or from sanctuary compartments where ART drugs may achieve suboptimal drug concentrations[13, 14]. In line with previous investigations, the multivariate analysis of our study showed that higher plasma VL at cohort entry and having suffered a previous AIDS episode were associated with low level viremia during otherwise suppressive ART. Interestingly, prior studies have found that higher VL at ART initiation correlates with reservoir size[15], giving support to the hypothesis that the frequency of viral loads elevations during ART may reflect the size of the pool of latently infected cells.

In a previous study[6] we showed that patients with low level viremia (LLV) between 200 and 499 copies/ml had a higher risk of virological failure, but we could not find such a relationship in patients with LLV between 50 and 199 copies/ml. In the previous analyses we used a stringent definition of virological failure consisting of at least 2 consecutive viral loads of more than 500 copies $/ \mathrm{mL}$. Current clinical guidelines, however, recommend a less lenient cutoff and define virological failure as the inability to maintain a VL below 200 copies/mL with a recommendation to switch ART if the VL is confirmed as being $\geq 200$ copies/mL[16]. Our present analyses were performed according to this cutoff and confirmed that even minor elevations of VL between 50 and 199 copies/ml, if they persist, are strongly associated with an increased risk of virological failure. Our results are in line with those found by Joya et al[17] in the US Military HIV Natural History Study (NHS) cohort, using the same definition of virological failure. They observed that having persistent elevated viremia between 50 and 199 copies $/ \mathrm{ml}$ in more than $25 \%$ of the measurements was associated with a higher risk of virological failure, compared to those who were suppressed or had an elevation of VL between 50 and 199 copies $/ \mathrm{ml}$ in less than $25 \%$ of the measurements. That study included mainly men (93\%) who initiated ART after 1996 and many of them were receiving old treatment regimens including unboosted $\mathrm{PI}$. In contrast, our dataset included only 
patients starting ART in this decade (after 2012) most of them receiving modern antiretroviral drugs, including INSTIs-based regimens, and a higher proportion of females than in the NHS cohort. In addition, we have evaluated the impact of very frequent VLE 50-199 (> 50\% of the measurements) and investigated the clinical implications of the viral load elevations.

Unlike most previous studies addressing implications of mild elevations of VL in which low-level viremia was considered as a dichotomous variable, we took into account the number of episodes in which the phenomenon was present as a potential surrogate marker of persistent viral replication. According to our results, the persistence of low-level viremia may be the major determinant of the outcome. Whereas a single elevation of VL might well be related to random variations of the technique or periods of low adherence that have no virological or clinical consequences $[14,18]$, frequent elevations, although of lowlevel and not consecutive, may be related to a larger reservoir size[13, 14, 19], a more advanced disease[14], a failure of the treatment to fully control viral replication or longer periods of nonadherence[14], and might therefore be associated with worse outcomes as it happened in our study.

As in our previous study[6], we found an association of LLV200-499 with the incidence of AIDS or death. However, we did not find an association with VLE50-199. An interesting finding of our study is that we observed higher rates of NAE in individuals with frequent and very frequent VLE 50-199, suggesting a link between persistent low-level viremia and the development of NAE, although this difference did not reach statistical significance. This signal goes in line with the hypothesis that NAE in HIV-infected patients receiving otherwise suppressive ART may be due in part to immune activation and inflammation resulting from persistence of viral replication or viral leaks from the reservoirs[18, 20, 21]. It is possible that other factors such as activation of latent viruses $[22,23]$ such as cytomegalovirus or human herpesvirus 8 , bacterial translocation and gut microbiota alteration along with low-level HIV replication play a role in the increase of inflammation and risk of NAE[24].

Our study has some limitations. Since the proportion of VLE may be related to the number of measurements, it may have been more likely to have higher proportions with a lower number of measurements. However, adjusting for this variable did not change the results of the Cox regression. We have disregarded the assay used for $V L$ determination during the study period in the participating centers and the type of technique could have influenced low-level viremia values. However, the detection threshold of 50 copies/ $\mathrm{ml}$ was used in all centers. Another potential limitation was that resistance data were not available in the CoRIS database in patients with low-level viremia. Some previous studies have found that those patients have a higher risk of developing drug resistance[25, 26] and it has been suggested that resistance mutations may increase the risk of virological failure [28,29]. Finally, we had no access to data on medication adherence and on several non-HIV associated factors that can affect the risk of NAE and mortality, such as smoking, alcohol or comorbidity scores. Therefore, we could not evaluate its potential influence on the outcomes.

In conclusion, in patients receiving modern ART, persistent VLE between 50 and 199 copies $/ \mathrm{ml}$ was strongly associated with virological failure but did not increase the risk of developing AIDS events or 
death. However, higher rates of NAE were observed. Those patients have to be monitored more closely and might be candidates to switching the antiretroviral regimen. Further research is required to investigate whether persistent VLE is associated with other adverse clinical outcomes.

\section{Declarations}

\section{Ackowledgements}

This study would not have been possible without the collaboration of all patients, medical and nursing staff and data managers who have taken part in the Project.

The RIS cohort (CoRIS) is supported by the Instituto de Salud Carlos III through the Red Temática de Investigación Cooperativa en Sida (RD06/006, RD12/0017/0018 and RD16/0002/0006) as part of the Plan Nacional R+D+I and cofinanced by ISCIII-Subdirección General de Evaluación y el FondoEuropeo de Desarrollo Regional (FEDER)

None of the authors of this manuscript have conflict of interest

\section{References}

1. Palella, F. J. et al. Declining morbidity and mortality among patients with advanced human immunodeficiency virus infection. HIV Outpatient Study Investigators. N Engl J Med. 338, 853-860 (1998).

2. INSIGHT START Study Group et al. Initiation of Antiretroviral Therapy in Early Asymptomatic HIV Infection. N Engl J Med. 373, 795-807 (2015).

3. Rodger, A. J. et al. Risk of HIV transmission through condomless sex in serodifferent gay couples with the HIV-positive partner taking suppressive antiretroviral therapy (PARTNER): final results of a multicentre, prospective, observational study. Lancet Lond Engl. 393, 2428-2438 (2019).

4. Boillat-Blanco, N. et al. Virological outcome and management of persistent low-level viraemia in HIV1-infected patients: 11 years of the Swiss HIV Cohort Study. Antivir Ther. 20, 165-175 (2015).

5. Antiretroviral Therapy Cohort Collaboration (ART-CC) et al. Impact of low-level viremia on clinical and virological outcomes in treated HIV-1-infected patients. AIDS Lond Engl. 29, 373-383 (2015).

6. Bernal, E. et al. Low-Level Viremia Is Associated With Clinical Progression in HIV-Infected Patients Receiving Antiretroviral Treatment. J Acquir Immune Defic Syndr 1999. 78, 329-337 (2018).

7. Santoro, M. M. et al. Reliability and clinical relevance of the HIV-1 drug resistance test in patients with low viremia levels. Clin Infect Dis Off Publ Infect Dis Soc Am. 58, 1156-1164 (2014).

8. Caro-Murillo, A. M. et al. [Spanish cohort of naïve HIV-infected patients (CoRIS): rationale, organization and initial results]. Enferm Infecc Microbiol Clin. 25, 23-31 (2007).

9. Masiá, M. et al. Risk, predictors, and mortality associated with non-AIDS events in newly diagnosed HIV-infected patients: role of antiretroviral therapy. AIDS Lond Engl. 27, 181-189 (2013). 
10. Cohen, C. Low-level viremia in HIV-1 infection: consequences and implications for switching to a new regimen. HIV Clin Trials. 10, 116-124 (2009).

11. Greub, G. et al. Intermittent and sustained low-level HIV viral rebound in patients receiving potent antiretroviral therapy. AIDS Lond Engl. 16, 1967-1969 (2002).

12. Taiwo, B. et al. Antiretroviral drug resistance in HIV-1-infected patients experiencing persistent lowlevel viremia during first-line therapy. J Infect Dis. 204, 515-520 (2011).

13. Sarmati, L., D'Ettorre, G., Parisi, S. G. \& Andreoni, M. HIV Replication at Low Copy Number and its Correlation with the HIV Reservoir: A Clinical Perspective. Curr HIV Res. 13, 250-257 (2015).

14. Ryscavage, P., Kelly, S., Li, J. Z., Harrigan, P. R. \& Taiwo, B. Significance and clinical management of persistent low-level viremia and very-low-level viremia in HIV-1-infected patients. Antimicrob Agents Chemother. 58, 3585-3598 (2014).

15. Gandhi, R. T. et al. Levels of HIV-1 persistence on antiretroviral therapy are not associated with markers of inflammation or activation. PLoS Pathog. 13, e1006285 (2017).

16. What's New in the Guidelines? Adult and Adolescent ARV. AIDSinfo.

https://aidsinfo.nih.gov/guidelines/html/1/adult-and-adolescent-arv/37/whats-new-in-theguidelines- (accessed 10 Mar 2020).

17. Joya, C. et al. Persistent Low-level Viremia While on Antiretroviral Therapy Is an Independent Risk Factor for Virologic Failure. Clin Infect Dis Off Publ Infect Dis Soc Am. 69, 2145-2152 (2019).

18. Ruelle, J. et al. HIV-1 low-level viraemia assessed with 3 commercial real-time PCR assays show high variability. BMC Infect Dis. 12, 100 (2012).

19. Bachmann, N. et al. Determinants of HIV-1 reservoir size and long-term dynamics during suppressive ART. Nat Commun. 10, 3193 (2019).

20. Hermans, L. E. et al. Effect of HIV-1 low-level viraemia during antiretroviral therapy on treatment outcomes in WHO-guided South African treatment programmes: a multicentre cohort study. Lancet Infect Dis. 18, 188-197 (2018).

21. Serrano-Villar, S. et al. Increased risk of serious non-AIDS-related events in HIV-infected subjects on antiretroviral therapy associated with a low CD4/CD8 ratio. PloS One. 9, e85798 (2014).

22. Masiá, M. et al. Coinfection with human herpesvirus 8 is associated with persistent inflammation and immune activation in virologically suppressed HIV-infected patients. PloS One. 9, e105442 (2014).

23. Patel, E. U. et al. Elevated cytomegalovirus IgG antibody levels are associated with HIV-1 disease progression and immune activation. AIDS Lond Engl. 31, 807-813 (2017).

24. Klatt, N. R., Chomont, N., Douek, D. C. \& Deeks, S. G. Immune activation and HIV persistence: implications for curative approaches to HIV infection. Immunol Rev. 254, 326-342 (2013).

25. Delaugerre, C. et al. Impact of low-level-viremia on HIV-1 drug-resistance evolution among antiretroviral treated-patients. PloS One. 7, e36673 (2012). 
26. Gallien, S. et al. Emerging integrase inhibitor resistance mutations in raltegravir-treated HIV-1-infected patients with low-level viremia. AIDS Lond Engl. 25, 665-669 (2011).

\section{Tables}


Table 1

Patient's characteristics at ART initiation ( $N=4121)$

\section{Uncommon VLE50-199 or not elevation}

$(3881 ; 94.2 \%)$
Frequent VLE50$199(185 ; 4.5 \%)$

485 (12.5)

\section{Very frequent VLE50-199}

$(55 ; 1.3 \%)$

\begin{tabular}{|c|c|c|c|c|}
\hline Sex female [n (\%)] & $485(12.5)$ & $23(12.4)$ & $3(5.5)$ & 0.290 \\
\hline $\begin{array}{l}\text { Transmission group [n } \\
(\%)]\end{array}$ & & & & 0.113 \\
\hline Homo/bisexual & 2667 (68.7) & $115(62.2)$ & $45(81.8)$ & \\
\hline Injecting drug use & $116(3.0)$ & $6(3.2)$ & $1(1.8)$ & \\
\hline Heteroxesual & $952(24.5)$ & $52(28.1)$ & $7(12.7)$ & \\
\hline Other/unknown & $146(3.8)$ & $12(6.5)$ & $2(3.6)$ & \\
\hline Country of origin [n (\%)] & & & & 0.857 \\
\hline Spain & $2366(61.0)$ & $112(60.5)$ & $30(54.5)$ & \\
\hline No Spain & $1497(38.6)$ & $72(38.9)$ & $25(45.5)$ & \\
\hline Unknown & $17(0.4)$ & $1(0.5)$ & $0(0.0)$ & \\
\hline Educational level [n (\%)] & & & & 0.147 \\
\hline $\begin{array}{l}\text { No or compulsory } \\
\text { education }\end{array}$ & $457(11.8)$ & $26(14.1)$ & $3(5.5)$ & \\
\hline $\begin{array}{l}\text { Upper secondary or } \\
\text { university }\end{array}$ & $2719(70.1)$ & $123(66.5)$ & $36(65.5)$ & \\
\hline Unknown & $705(18.2)$ & $36(19.5)$ & $16(29.1)$ & \\
\hline AIDS diagnosis [n (\%)] & $367(9.5)$ & $33(17.8)$ & $10(18.2)$ & $\begin{array}{l}<.001 \\
0.001\end{array}$ \\
\hline ART regimen [n (\%)] & & & & $\begin{array}{l}< \\
0.001\end{array}$ \\
\hline $2 \mathrm{NRTI}+1 \mathrm{PI} / \mathrm{b}$ & $672(17.3)$ & $40(21.6)$ & $11(20.0)$ & \\
\hline 2 NRTI + 1 NNRTI & $1541(39.7)$ & $44(23.8)$ & $8(14.5)$ & \\
\hline $2 \mathrm{NRTI}+$ INSTIS & $1447(37.3)$ & $89(48.1)$ & $35(63.6)$ & \\
\hline
\end{tabular}

\section{$\mathrm{p}-$
value}

value 


\begin{tabular}{|c|c|c|c|c|}
\hline & $\begin{array}{l}\text { Uncommon VLE50-199 } \\
\text { or not elevation } \\
(3881 ; 94.2 \%)\end{array}$ & $\begin{array}{l}\text { Frequent VLE50- } \\
199(185 ; 4.5 \%)\end{array}$ & $\begin{array}{l}\text { Very frequent } \\
\text { VLE50-199 } \\
(55 ; 1.3 \%)\end{array}$ & $\begin{array}{l}\mathrm{p} \text { - } \\
\text { value }\end{array}$ \\
\hline Other/unknown & $221(5.7)$ & $12(6.5)$ & $1(1.8)$ & \\
\hline $\begin{array}{l}\text { Time HIV infection, } \\
\text { years (median [IQR]) }\end{array}$ & $3.6[2.2,5.5]$ & $3.1[1.9,4.9]$ & $1.8[1.2,2.8]$ & $<.001$ \\
\hline $\begin{array}{l}\text { Years on ART (median } \\
\text { [IQR]) }\end{array}$ & $2.6[1.5,3.8]$ & $2.4[1.5,3.5]$ & $1.2[0.9,2.0]$ & $<.001$ \\
\hline $\begin{array}{l}\text { CD4 + cell count } \\
\text { (median [IQR]) }\end{array}$ & $397[262,548]$ & $331[127,524.7]$ & $\begin{array}{l}353[222, \\
467.5]\end{array}$ & $\begin{array}{l}< \\
0.001\end{array}$ \\
\hline CD4 + cell count [n (\%)] & & & & $\begin{array}{l}< \\
0.001\end{array}$ \\
\hline$<200$ & $654(16.9)$ & $60(32.4)$ & $10(18.2)$ & \\
\hline $200-499$ & $1942(50.0)$ & $72(38.9)$ & $35(63.6)$ & \\
\hline$>=500$ & $1190(30.7)$ & $52(28.1)$ & $9(16.4)$ & \\
\hline Unknown & $95(2.4)$ & $1(0.5)$ & $1(1.8)$ & \\
\hline $\begin{array}{l}\text { Hepatitis C virus } \\
\text { antibodies [n (\%)] }\end{array}$ & & & & 0.568 \\
\hline No & $3262(84.1)$ & 151 (81.6) & $47(85.5)$ & \\
\hline Yes & $229(5.9)$ & $16(8.6)$ & $2(3.6)$ & \\
\hline Unknown & $390(10.0)$ & $18(9.7)$ & $6(10.9)$ & \\
\hline HIV-1 viral load [n (\%)] & & & & $<0.001$ \\
\hline$<100000$ & $2625(67.6)$ & $69(37.3)$ & $19(34.5)$ & \\
\hline$>=100000$ & $1135(29.2)$ & $115(62.2)$ & $35(63.6)$ & \\
\hline Unknown & $121(3.1)$ & $1(0.5)$ & $1(1.8)$ & \\
\hline $\begin{array}{l}\text { Age, years (median } \\
{[\mathrm{IQR})}\end{array}$ & $35[28,42]$ & $38[29,45]$ & $35[28,42]$ & 0.059 \\
\hline Age $>=50$ years [n (\%)] & $422(10.9)$ & $22(11.9)$ & $4(7.3)$ & 0.627 \\
\hline
\end{tabular}

VLE50-199: viral load elevation between 50 and 199 copies/ml; Uncommon VLE50-199, viral load elevation between 50 and $199 \mathrm{copies} / \mathrm{ml}$ in <25\% of measurements or not VLE; Frequent VLE50-199, viral load elevation between 50 and $199 \mathrm{copies} / \mathrm{ml}$ between $25-50 \%$ of measurements; Very frequent VLE50-199, viral load elevation between 50 and 199 copies $/ \mathrm{ml}$ in $>50 \%$ of measurements; ART: Antiretroviral therapy; NRTI: Nucleoside reverse transcriptase inhibitors NNRTI: Non-nucleoside reverse transcriptase inhibitors; PI/b: Ritonavir or cobicistat booster-Protease inhibitor; INSTIs: Integrase inhibitor 


\begin{tabular}{|c|c|c|c|c|}
\hline & $\begin{array}{l}\text { Uncommon VLE50-199 } \\
\text { or not elevation } \\
(3881 ; 94.2 \%)\end{array}$ & $\begin{array}{l}\text { Frequent VLE50- } \\
199(185 ; 4.5 \%)\end{array}$ & $\begin{array}{l}\text { Very frequent } \\
\text { VLE50-199 } \\
(55 ; 1.3 \%)\end{array}$ & $\begin{array}{l}\mathrm{p}- \\
\text { value }\end{array}$ \\
\hline \multicolumn{4}{|l|}{$\begin{array}{l}\text { Hepatitis B surface } \\
\text { antigen [n (\%)] }\end{array}$} & 0.978 \\
\hline No & $3106(80.0)$ & $150(81.1)$ & $45(81.8)$ & \\
\hline Yes & $112(2.9)$ & $5(2.7)$ & $2(3.6)$ & \\
\hline Unknown & $663(17.1)$ & $30(16.2)$ & 8 (14.5) & \\
\hline \multicolumn{5}{|c|}{$\begin{array}{l}\text { VLE50-199: viral load elevation between } 50 \text { and } 199 \text { copies/ml; Uncommon VLE50-199, viral load } \\
\text { elevation between } 50 \text { and } 199 \text { copies/mI in < } 25 \% \text { of measurements or not VLEF; Frequent VLE50-199, } \\
\text { viral load elevation between } 50 \text { and } 199 \text { copies/ml between } 25-50 \% \text { of measurements; Very frequent } \\
\text { VLE50-199, viral load elevation between } 50 \text { and } 199 \text { copies/mI in > } 50 \% \text { of measurements; ART: } \\
\text { Antiretroviral therapy; NRTI: Nucleoside reverse transcriptase inhibitors NNRTI: Non-nucleoside reverse } \\
\text { transcriptase inhibitors; PI/b: Ritonavir or cobicistat booster-Protease inhibitor; INSTIs: Integrase } \\
\text { inhibitor }\end{array}$} \\
\hline
\end{tabular}


Table 2

Adjusted hazard ratios for virological failure, AIDS events/death and non-AIDS events

\begin{tabular}{|c|c|c|c|c|c|c|}
\hline & Virological fa & ure & AIDS events/ & ath & Non-AID: & ents \\
\hline & $\mathrm{HR}(\mathrm{Cl} 95 \%)$ & p & $\mathrm{HR}(\mathrm{Cl} 95 \%)$ & p & $\begin{array}{l}\mathrm{HR}(\mathrm{Cl} \\
95 \%)\end{array}$ & $\mathbf{p}$ \\
\hline Transmission group & 1 & 0.089 & 1 & 0.224 & 1 & 0.551 \\
\hline Homo/bisexual & $\begin{array}{l}1.81(0.91- \\
3.60)\end{array}$ & 0.001 & $\begin{array}{l}0.26(0.03- \\
2.27)\end{array}$ & 0.145 & $\begin{array}{l}1.36 \\
(0.50-\end{array}$ & 0.561 \\
\hline Injecting drug use & $1.73(1.23-$ & 0.793 & $1.54(0.86-$ & 0.499 & 3.70) & 0.956 \\
\hline Heterosexual & $2.43)$ & & $2.77)$ & & $\begin{array}{l}1.14 \\
073-\end{array}$ & \\
\hline Other/unknown & $\begin{array}{l}0.87(0.31- \\
2.41)\end{array}$ & & $\begin{array}{l}0.62(0.15- \\
2.45)\end{array}$ & & 1.79) & \\
\hline & & & & & $\begin{array}{l}0.97 \\
(0.34- \\
2.74)\end{array}$ & \\
\hline AIDS diagnosis & $\begin{array}{l}1.58(1.02- \\
2.40)\end{array}$ & 0.039 & $\begin{array}{l}51.23 \\
(26.11- \\
100.54)\end{array}$ & $\begin{array}{l}<.001 \\
0.01\end{array}$ & $\begin{array}{l}1.4 \\
(0.76- \\
2.58)\end{array}$ & 0.275 \\
\hline Time on ART & $\begin{array}{l}0.04(0.02- \\
0.06)\end{array}$ & $<.001$ & $\begin{array}{l}0.61(0.48- \\
0.77)\end{array}$ & $<.001$ & $\begin{array}{l}0.79 \\
(0.62-1)\end{array}$ & 0.05 \\
\hline
\end{tabular}

${ }^{1}$ Adjusted for sex (male, female), age $(<50, \geq 50$ ), transmission group (homo/bisexual, injecting drug use, heterosexual, other/unknown), educational level (no or compulsory education, upper secondary or university, unknown), country of origin (Spain, no Spain, Unknown), CD $4+$ cell count $(<200, \geq 200$, unknown), HIV-1 viral load (<100000, $\geq 100000$, unknown), AIDS diagnosis (no, yes), hepatitis C virus antibodies (no, yes, unknown) and hepatitis B surface antigen (no, yes, unknown) at ART initiation, ART regimen (2 NRTI + 1 NNRTI, 2 NRTI + 1 PI, 2 NRTI + 1 INSTI, other/non-specified), VLE50-199, VLE200-999 and numbers of measurements.

VLE: Viral load elevation; VLE50-199, viral load elevation between 50 and 199 copies; Uncommon VLE50-199, viral load elevation between 50 and $199 \mathrm{copies} / \mathrm{ml}$ in $<25 \%$ of measurements or not VLE; Frequent VLE50-199, viral load elevation between 50 and 199 copies $/ \mathrm{ml}$ between $25-50 \%$ of measurements; Very frequent VLE50-199, viral load elevation between 50 and $199 \mathrm{copies} / \mathrm{ml}$ in >50\% of measurements

VLE200-999 viral load elevation between 200 and 999 copies/ml; ART: Antirretroviral therapy; NRTI: Nucleoside reverse transcriptase inhibitors NNRTI: Non-nucleoside reverse transcriptase inhibitors; PI/b: Ritonavir or cobicistat booster-Protease inhibitor; INSTI: Integrase inhibitor 


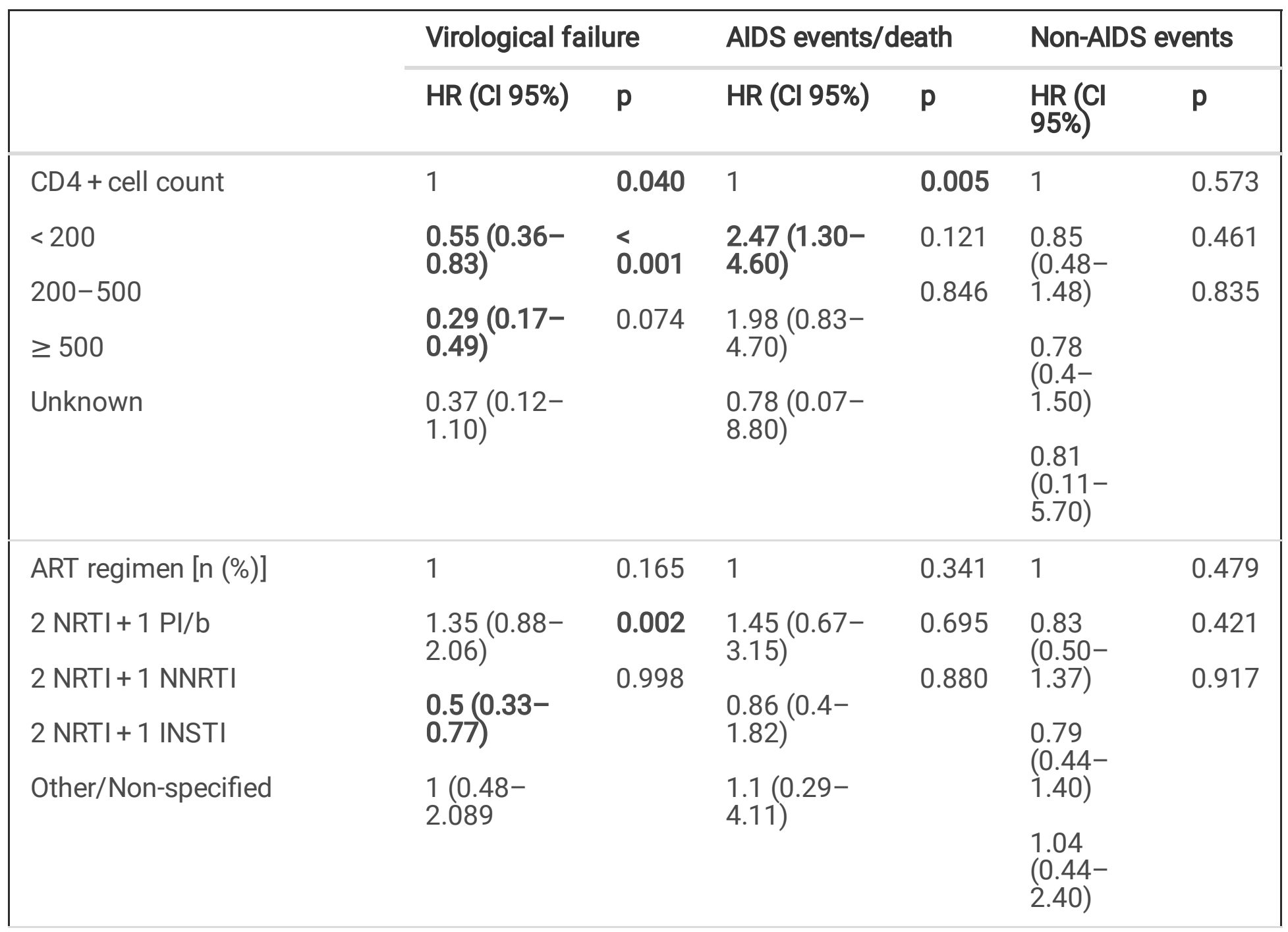

${ }^{1}$ Adjusted for sex (male, female), age $(<50, \geq 50$ ), transmission group (homo/bisexual, injecting drug use, heterosexual, other/unknown), educational level (no or compulsory education, upper secondary or university, unknown), country of origin (Spain, no Spain, Unknown), CD4 + cell count ( $<200, \geq 200$, unknown), HIV-1 viral load ( $<100000, \geq 100000$, unknown), AIDS diagnosis (no, yes), hepatitis C virus antibodies (no, yes, unknown) and hepatitis B surface antigen (no, yes, unknown) at ART initiation, ART regimen (2 NRTI + 1 NNRTI, 2 NRTI + 1 PI, 2 NRTI + 1 INSTI, other/non-specified), VLE50-199, VLE200-999 and numbers of measurements.

VLE: Viral load elevation; VLE50-199, viral load elevation between 50 and 199 copies; Uncommon VLE50-199, viral load elevation between 50 and $199 \mathrm{copies} / \mathrm{ml}$ in $<25 \%$ of measurements or not VLE; Frequent VLE50-199, viral load elevation between 50 and 199 copies $/ \mathrm{ml}$ between $25-50 \%$ of measurements; Very frequent VLE50-199, viral load elevation between 50 and $199 \mathrm{copies} / \mathrm{ml}$ in $>50 \%$ of measurements

VLE200-999 viral load elevation between 200 and 999 copies/ml; ART: Antirretroviral therapy; NRTI: Nucleoside reverse transcriptase inhibitors NNRTI: Non-nucleoside reverse transcriptase inhibitors; PI/b: Ritonavir or cobicistat booster-Protease inhibitor; INSTI: Integrase inhibitor 


\begin{tabular}{|c|c|c|c|c|c|c|}
\hline & \multicolumn{2}{|c|}{ Virological failure } & \multicolumn{2}{|c|}{ AIDS events/death } & \multicolumn{2}{|c|}{ Non-AIDS events } \\
\hline & HR (CI 95\%) & $\mathbf{p}$ & HR (CI 95\%) & $\mathbf{p}$ & $\begin{array}{l}\mathrm{HR}(\mathrm{Cl} \\
95 \%)\end{array}$ & $\mathbf{p}$ \\
\hline \multirow{4}{*}{$\begin{array}{l}\text { HIV-1 viral load } \\
<100000 \\
\geq 100000 \\
\text { Unknown }\end{array}$} & 1 & 0.032 & 1 & 0.02 & 1 & 0.557 \\
\hline & $\begin{array}{l}1.48(1.03- \\
2.11)\end{array}$ & \multirow[t]{3}{*}{0.030} & $\begin{array}{l}0.49(0.27- \\
0.89)\end{array}$ & \multirow[t]{3}{*}{0.303} & $\begin{array}{l}0.87 \\
0.55-\end{array}$ & \multirow[t]{3}{*}{0.909} \\
\hline & \multirow{2}{*}{$\begin{array}{l}2.48(1.09- \\
5.60)\end{array}$} & & \multirow{2}{*}{$\begin{array}{l}0.38(0.06- \\
2.37)\end{array}$} & & 1.36) & \\
\hline & & & & & $\begin{array}{l}0.91 \\
(0.18- \\
4.50)\end{array}$ & \\
\hline \multirow{3}{*}{$\begin{array}{l}\text { VLE50-199 } \\
\text { Uncommon VLE50-199 or } \\
\text { not elevation } \\
\text { Frequent VLE50-199 Very } \\
\text { frequent VLE50-199 }\end{array}$} & 1 & \multirow{3}{*}{$\begin{array}{l}<.001 \\
<.001\end{array}$} & \multirow{3}{*}{$\begin{array}{l}1.07(0.30- \\
3.80) \\
\text { NA }\end{array}$} & 0.911 & 1 & 0.081 \\
\hline & $\begin{array}{l}11.83 \\
(6.42- \\
21.84)\end{array}$ & & & \multirow[t]{2}{*}{0.911} & $\begin{array}{l}2.13 \\
(0.91- \\
4.97)\end{array}$ & \multirow[t]{2}{*}{0.052} \\
\hline & $\begin{array}{l}29.10 \\
(12.60- \\
67.19)\end{array}$ & & & & $\begin{array}{l}4.66 \\
(0.90- \\
21.90)\end{array}$ & \\
\hline \multicolumn{7}{|c|}{$\begin{array}{l}1 \text { Adjusted for sex (male, female), age }(<50, \geq 50 \text { ), transmission group (homo/bisexual, injecting drug } \\
\text { use, heterosexual, other/unknown), educational level (no or compulsory education, upper secondary } \\
\text { or university, unknown), country of origin (Spain, no Spain, Unknown), CD } 4+\text { cell count ( }<200, \geq 200 \text {, } \\
\text { unknown), HIV-1 viral load ( }<100000, \geq 100000 \text {, unknown), AIDS diagnosis (no, yes), hepatitis C virus } \\
\text { antibodies (no, yes, unknown) and hepatitis B surface antigen (no, yes, unknown) at ART initiation, } \\
\text { ART regimen ( } 2 \text { NRTI + } 1 \text { NNRTI, } 2 \text { NRTI + } 1 \text { PI, } 2 \text { NRTI + } 1 \text { INSTI, other/non-specified), VLE50-199, } \\
\text { VLE200-999 and numbers of measurements. }\end{array}$} \\
\hline \multicolumn{7}{|c|}{$\begin{array}{l}\text { VLE: Viral load elevation; VLE50-199, viral load elevation between } 50 \text { and } 199 \text { copies; Uncommon } \\
\text { VLE50-199, viral load elevation between } 50 \text { and } 199 \text { copies } / \mathrm{ml} \text { in }<25 \% \text { of measurements or not VLE; } \\
\text { Frequent VLE50-199, viral load elevation between } 50 \text { and } 199 \mathrm{copies} / \mathrm{ml} \text { between } 25-50 \% \text { of } \\
\text { measurements; Very frequent VLE50-199, viral load elevation between } 50 \text { and } 199 \mathrm{copies} / \mathrm{ml} \text { in }>50 \% \\
\text { of measurements }\end{array}$} \\
\hline \multicolumn{7}{|c|}{$\begin{array}{l}\text { VLE200-999 viral load elevation between } 200 \text { and } 999 \text { copies/ml; ART: Antirretroviral therapy; NRTI: } \\
\text { Nucleoside reverse transcriptase inhibitors NNRTI: Non-nucleoside reverse transcriptase inhibitors; } \\
\text { PI/b: Ritonavir or cobicistat booster-Protease inhibitor; INSTI: Integrase inhibitor }\end{array}$} \\
\hline
\end{tabular}

\section{Figures}



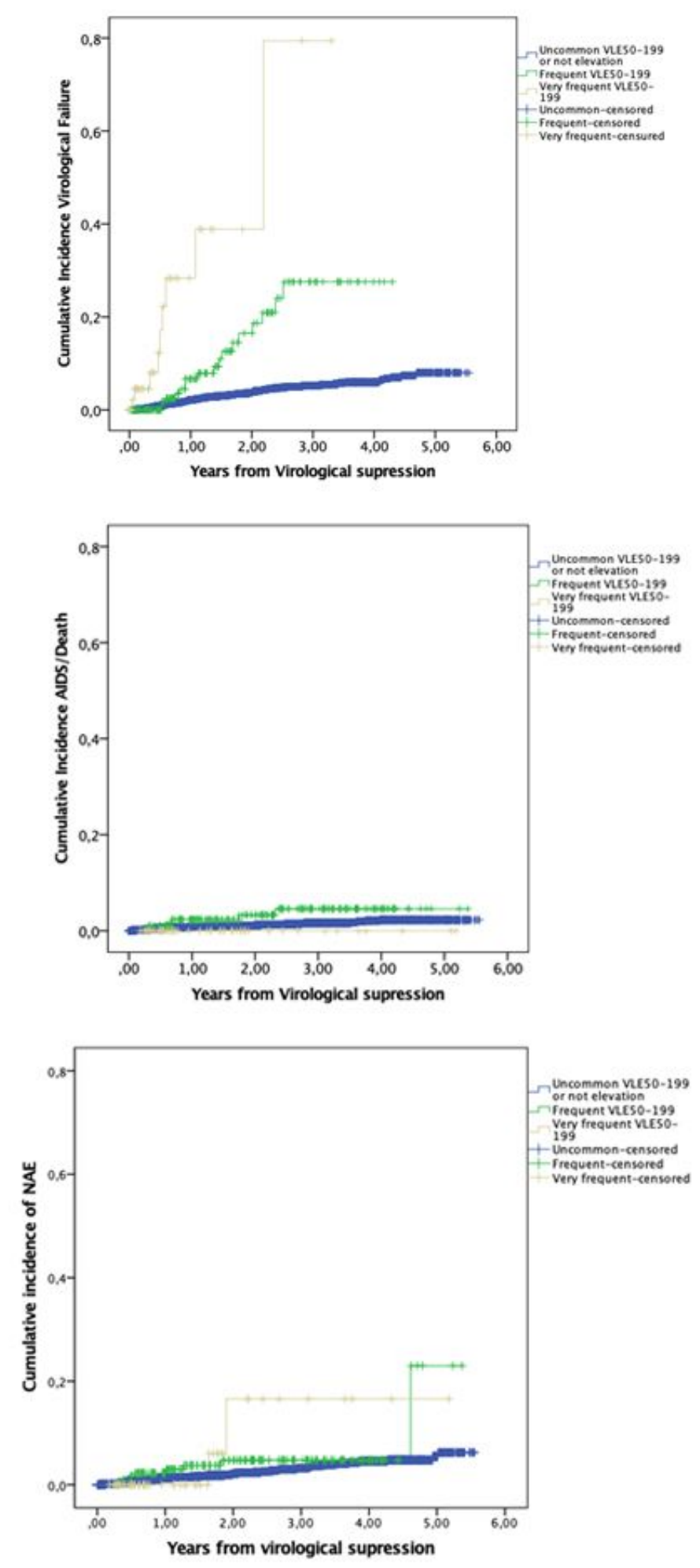

\section{Figure 1}

A. Cause-specific cumulative incidence of first virological failure after virological suppression B. Cumulative incidence of first AIDS event/death after virological suppression C. Cumulative incidence of first Non-AIDS event after virological suppression NAEs: Non-AIDS events; VLE50-199: viral load elevation between 50 and 199 copies/ml; Uncommon VLE50-199, viral load elevation between 50 and 199 copies/ml in $<25 \%$ of measurements or not VLE; Frequent VLE50-199, viral load elevation between 50 and 
199 copies/ml between 25-50\% of measurements; Very frequent VLE50-199, viral load elevation between 50 and 199 copies/ml in > 50\% of measurements; 